\title{
The decline and impending extinction of the South China tiger
}

\author{
Ronald Tilson, Kathy Traylor-Holzer and Qiu Ming Jiang
}

The South China tiger Panthera tigris amoyensis is the rarest of the five living tiger subspecies, the most critically threatened and the closest to extinction. No wild South China tigers have been seen by officials for 25 years and one was last brought into captivity 27 years ago. The 19 reserves listed by the Chinese Ministry of Forestry within the presumed range of the tiger are spatially fragmented and most are too small to support viable tiger populations. Over the last 40 years wild populations have declined from thousands to a scattered few. Despite its plight and occasional anecdotal reports of sightings by local people, no intensive field study has been conducted on this tiger subspecies and its habitat. The captive population of about 50 tigers, derived from six wild-caught founders, is genetically impoverished with low reproductive output. Given the size and fragmentation of potential tiger habitat, saving what remains of the captive population may be the only option left to prevent extinction of this tiger subspecies, and even this option is becoming increasingly less probable. This precarious dilemma demands that conservation priorities be re-evaluated and action taken immediately to decide if recovery of the wild population will be possible.

\section{Decline of the wild population}

Compared with other tiger range countries, China is unique in that it has four of the living tiger subspecies within its borders. The Siberian tiger Panthera tigris altaica occurs in the far north-east on the borders with Russia and North Korea; the Indochinese tiger P.t. corbetti occurs in the south-east, bordering Vietnam and Lao PDR; and the Bengal tiger P.t. tigris is found in the extreme south-west bordering India and Myanmar ( $\mathrm{Lu}$ and Sheng, 1986). The fourth subspecies, the South China tiger P.t. amoyensis, is restricted to the subtropical areas of China and is considered to be the evolutionary antecedent of all tigers (Herrington, 1987). Formerly the most common subspecies in China, this tiger has all but disappeared in the wild except in part of Fujian province and possibly in adjacent areas as a result of overhunting and habitat destruction ( $\mathrm{Lu}$ and Sheng, 1986; Wang and Wang, 1986; Wang Menghu, pers. comm.).
The status of wild South China tigers in 1997 is vague. Legends, such as those of the popular Chinese hero Wu Song the tiger killer recounted in the Ming Dynasty novel Outlaws of the Marsh, have inspired fear and relentless hunting of the tiger throughout its existence in China ( $\mathrm{Li}$ and Zhao, 1989). In the early 1950s the South China tiger was reputed to number more than 4000 when it became the target of many large-scale 'anti-pest' government campaigns (Lu and Sheng, 1986; Tan, 1987). Official government statistics documented the decline of the South China tiger by the number of tiger skins taken, from about 80 skins per year in the early 1950s to four skins per year in the early 1970s, representing only a fraction of tigers killed in China. Altogether, about 3000 tigers are estimated to have been killed during this 30-year period ( $\mathrm{Lu}$ and Sheng, 1986). The effects of uncontrolled hunting were compounded by extensive deforestation and probable reduction in available prey, leading to population fragmentation and 
increased vulnerability to local extinction due to stochastic events. This resulted in a rapid decline in the wild tiger population, and by 1982 only an estimated 150-200 wild South China tigers remained ( $\mathrm{Lu}$ and Sheng, 1986).

The Chinese government was slow to respond. The Siberian tiger was listed as a rare and precious species in Ministry of Forestry documents as early as 1969. In 1975 the 'Regulation Regarding the Protection of Wildlife Resources' classified the South China tiger as a third category species 'i.e. protected by controlled hunting'. In 1973 it was upgraded to second category level i.e. a protected and prohibited from hunting species'. In 1979 it achieved first category status of full protection but this was ineffective because hunters neither accepted nor respected the regulation, and wild tiger numbers continued to decline (Lu and Sheng, 1986).

Population estimates continued to decline through the 1980s, despite its listing as Category I on China's national register of endangered animals and the creation of three reserves for its protection (Chebaling Reserve, Guangdong province [75 sq km]; Bamianshan Reserve, Hunan province [200 sq km]; and Jingangshan Reserve, Jiangxi province [159 sq $\mathrm{km}]$; Lu and Sheng, 1986; Lu, 1987; Li and Zhao, 1989). Evidence of wild tigers in central China was scattered and seldom confirmed. Tan (1987) summarized a number of isolated reports of wild South China tigers between 1981 and 1986:

- in January 1981 three cubs killed, Chingxi Commune, Dapu county, Guangdong;

- in 1982-83 tiger traces reported in Bamianshan Nature Reserve, Hunan;

- in May 1984 tigress and three cubs sighted, two of cubs captured, Anhua county, Hunan;

- in summer 1984 tiger sighted, traces found, Anyang Mountain, Suining county, Hunan;

- in December 1984 wounded tiger captured, died, Zhenxiong county, Yunnan;

- in 1984 tiger scat found, Shixing Nature Reserve, Guangdong; in spring 1985 large male sighted, $4-6$ tigers believed in or around reserve;

- in February 1986 two wild-caught cubs (one alive, one dead) observed in cage for sale at a bus station, Pucheng county, Fujian;

- in April 1986 news report of many recent tiger sightings, Lichuan and Tongcheng counties, Hubei.

Crude population estimates based upon such scant information suggested that fewer than 50-80 wild South China tigers remained in 1986 (Lu, 1987). In 1993 the IUCN Cat Specialist Group, citing numbers given by Chinese biologists, continued to put the population at 30-80 (Jackson, 1993; Nowell and Jackson, 1996).

More recent surveys found a few signs of tigers (and possibly tiger cubs) in 11 protected areas in the remote mountains of Guangdong, Hunan and Fujian provinces (Koehler, 1991; Gui and Meng, 1993). No tigers were directly observed; evidence was limited to sightings of tracks, scrapings and reported sightings by local people. Remnant populations are now believed to occupy montane subtropical evergreen forests within 19 protected areas situated along transprovincial boundaries of Guangdong, Fujian, Jiangxi and Hunan provinces (Gui and Meng, 1993). Two other protected areas, Shennongjia in Hubei province and Mt Fanjing in Fujian province, fall outside this range. These sites are separated from each other by agricultural or deforested areas (Koehler, 1991) and are, for the most part, too small to maintain viable tiger populations (14 are c. $100 \mathrm{sq} \mathrm{km}$ or less; the other five range from 180 to $705 \mathrm{sq} \mathrm{km}$ ).

Population viability modelling (Seal et al., 1994; Kenney et. al., 1995) suggests that small tiger populations (fewer than 100 individuals) are highly vulnerable to stochastic events and poaching, and have a high probability of extinction without genetic and demographic supplementation. Even if tigers in these areas live at saturation levels with a high density of prey species, their populations would probably be too small to be viable. In general, tigers live at varying population densities, depending on the quality of the habitat, ranging from 10-15 per $100 \mathrm{sq} \mathrm{km}$ in India (Sankala, 1979; Karanth, 1997), and 6-7 per $100 \mathrm{sq} \mathrm{km}$ in Nepal (McDougal, 1977; Smith, 1978; Sunquist, 1981), to $1-4$ per $100 \mathrm{sq} \mathrm{km}$ in 
Sumatra (Santiapillai and Widodo, 1987; Griffiths, 1994; Franklin et al., 1997) to as low as 0.25 male tigers per $100 \mathrm{sq} \mathrm{km}$ in Russia (Miquelle et al., 1997). Twelve additional sites totalling $6000 \mathrm{sq} \mathrm{km}$ have been recommended for preservation as potential tiger habitat (Gui and Meng, 1993), but the wild population may be too small and fragmented to recover on its own, even with additional protected habitat.

An unconfirmed report in 1995 from the Chinese Ministry of Forestry suggested that 6-13 tigers remain in Jiangxi province with another 4-5 tigers in Fujian, Guangdong and Hunan provinces - a total of fewer than 20 individuals left in the wild. This estimate is based upon secondary tiger signs observed during 147 survey days over 2 years and represents the most recent survey data for South China tigers. This is clearly a spiral to extinction for the wild population.

\section{Traditional Chinese medicine}

The use of tiger products in traditional Chinese medicine has certainly contributed to the decline of the South China tiger and is considered by some authorities to be the most serious threat to the tiger's survival, eclipsing habitat loss (Mills and Jackson, 1994; Henley and Mills, 1997). Although almost all parts of the tiger, from whiskers to faeces, are used in age-old medicines, tiger bone is the most valued as a treatment for various conditions such as rheumatism (Mills and Jackson, 1994; Mainka and Mills, 1995). Consumption of tiger bone has increased in recent years and continues today as both human population and per capita expendable income have increased dramatically in East Asia in concert with a resurgence of interest in traditional cures (Mills and Jackson, 1994; Henley and Mills, 1997). China is not only a consumer, but also the world's largest exporter of tiger bone and other tiger derivatives, exporting over 27 million units of tiger medicines and wine to 26 countries and territories in 1990-92 (Mills and Jackson, 1994). Ironically, analyses conducted by the National Forensics Laboratory of the US Fish and Wildlife Service have not yet found any detectable levels of bone in samples of tigerbased pharmaceuticals but have revealed high levels of toxic metals, particularly arsenic (Espinoza et al., 1994).

Trade in tiger products has continued despite the Appendix I listing for tigers under the Convention on International Trade of Endangered Species of Wild Fauna and Flora (CITES). Efforts have been made, however, to curb consumption of tiger products. At the 1994 CITES Conference of the Parties, a resolution was passed to work with traditional medicine communities to eliminate the use of tiger bone (Mainka and Mills, 1995). In March 1995 the governments of China and India signed a Protocol on the Conservation of the Tiger, which included a crackdown on illegal poaching and trafficking of tiger products. Recent newspaper articles in China report on the apprehension and execution of poachers dealing in tiger products.

The demand for tiger products led to proposals for tiger farms in several Asian countries to provide a captive source of tiger derivatives. Controversy surrounded the establishment of the Hengdaohezi Breeding Centre of Felidae Animals in Heilongjiang province near Harbin, China (Martin et al., 1991). This centre has raised about 70 Siberian tigers: 30 remain at the centre, 30 have been transferred to a newly established Siberian Tiger Park in Harbin and 10 were moved to Shanghai Zoo (Jackson, 1996). It is reported that these tigers are being bred and maintained for eventual reintroduction efforts in northern China (Liu, 1993; Anon., 1994b). The conservation value of these kinds of breeding centres as well as the entire issue of tiger farming have sparked heated debate (Day, 1994; P. Jackson, pers. comm.). All captive South China tigers, however, are maintained by zoos participating in the Chinese Association of Zoological Gardens and are not connected with any 'tiger farms' (Wang et al., 1995).

\section{History of the captive population}

The decline of the tiger in China prompted a symposium on the conservation of the South 
China tiger held in Chongqing in October 1984 by the Zoological Society of Sichuan and the Wildlife Conservation Association of Sichuan. The South China Tiger Conservation Co-ordination Group was formed at the meeting to manage the captive population but it accomplished very little other than recommending the development of a central breeding facility (Tan, 1987). In the same year the Chinese Ministry of Urban and Rural Construction and Environmental Protection (MURCEP) approved the construction of a South China tiger research and breeding centre at Chongqing Zoological Garden, but no funds were available for the project (Tan, 1987).

The critical situation of the captive South China tiger population was revisited at the 1986 international symposium, World Conservation Strategies for Tigers (Tilson and Seal, 1987), and nothing was done. Tan (1987), reviewed the status of captive South China tigers and noted numerous problems, such as an uneven sex ratio favouring males, numerous tigers that were housed singly rather than paired for breeding and high levels of inbreeding. A recovery programme for the South China tiger proposed by Xiang et al. (1987) acknowledged the need for wildlife conservation legislation, field surveys and protected areas, but focused primarily on the construction of a large central breeding facility for management of the captive population as proposed in 1984. The Chinese found no international support for funds to build and maintain such a facility, and no progress was made to organize further the management of the captive South China tiger population.

Until 1995, the precise status of captive South China tigers was unclear. At that time the International Tiger Studbook (Müller, 1994) listed 36 living South China tigers, all in Chinese zoos. Completeness of the data was suspect because no births and little other information had been reported since 1985 . Studbook pedigrees indicated that the captive population was derived from six or eight wild-caught founders (it was uncertain whether or not two founders had reproduced after 1985). No new founders had been brought into captivity since 1970 . There was no official studbook keeper in China, and reports to the International Tiger Studbook were irregular and incomplete, making analysis of the population impossible.

In 1995 the Chinese Association of Zoological Gardens (CAZG) invited the IUCN/SSC Conservation Breeding Specialist Group (CBSG) to help develop a captive management programme. An international team of tiger zoo specialists was formed and two 2-week visits to the four primary Chinese zoos (Guangzhou, Chongqing, Shanghai and Suzhou) holding South China tigers were scheduled. During the first visit the team verified the origin and parentage of each tiger through meetings with zoo staff and personal inspection of animal records (Wang et al., 1995), and oversaw the update of the CAZG South China Tiger Studbook (Li, 1995). On the second visit the team performed medical and reproductive evaluations on as many tigers as possible, reviewed each zoo's daily and long-term tiger health plans and quality of their facilities, and provided extensive training for staff in veterinary and husbandry procedures (Armstrong et al., 1996; Tilson et al., 1996).

Based on demographic and genetic analyses of the revised studbook, the CAZG set specific 5 - and 10-year goals to retain 90 per cent of the current genetic diversity in the captive population (which has already lost 22 per cent of its genetic diversity). Using this information the CAZG drafted a preliminary South China Tiger Masterplan (Wang et al., 1995), which outlined recommendations for tiger identification and record-keeping, medical and management procedures, reproductive evaluation and genome banking, and training needs. This masterplan and the accompanying CAZG South China Tiger Ex Situ Conservation Strategy recommended effective captive management of the South China tiger through institutional co-operation and renovation of existing facilities rather than by development of a central breeding facility (Wang et al., 1995). Most importantly, the remaining captive tigers were recognized as being the only back-up for the recovery of the wild population. 


\section{Assessment of medical and husbandry practices}

As part of the evaluation process and training programme for Chinese zoo staff, physical examinations, tiger identification and biomaterial collection procedures were performed on 22 of the 50 captive South China tigers (Armstrong et al., 1996; Tilson et al., 1996). The first priority to safeguard tiger health was to establish minimum medical management criteria for tigers, including programmes for physical examinations, vaccinations for feline rhinotracheitis, calicivirus, panleukopenia and rabies, blood and serum chemistry tests, and parasite screening. Also important were repair procedures for fractured teeth and establishment of a medical records database.

Evaluation of animal records and recordkeeping methods at each zoo revealed that records were incomplete or not standardized. Issues of concern regarding records included individual animal identification, record standardization, tiger pedigree verification, and records of breeding attempts and success.

Tiger exhibits, holding areas, medical facilities and husbandry practices were evaluated. Overall, tiger facilities and management appeared adequate, but a more complete nutritional analysis needed to be carried out. The CAZG has chosen to model their tiger husbandry and medical procedures on guidelines in Management and Conservation of Captive Tigers (Tilson et al., 1995), which now has been translated into Chinese (Qiu Ming Jiang, pers. comm.). Additional zoo staff training is needed in medical and dental care, nutrition, husbandry, genetic analysis and assisted reproductive techniques (Armstrong et al., 1996).

\section{Male reproductive evaluation}

While conducting tiger medical evaluations, 11 adult male tigers were electroejaculated and their semen collected. Analysis revealed a wide range of semen quality among males (Byers et al., 1996). Two produced no sperm, two produced too few sperm to count and another showed no sperm movement. When compared with normal mean values for captive Siberian and Sumatran tigers (given in parentheses) reported by Wildt et al., 1995, the mean volume for the nine ejaculates that contained sperm was typical at $6.4 \mathrm{ml}$ (normal mean $=6.9 \pm 0.6 \mathrm{ml}$ for Siberian, $5.6 \pm 0.7 \mathrm{ml}$ for Sumatran). Spermic concentration varied from fewer than one million $/ \mathrm{ml}$ to 22 million sperm $/ \mathrm{ml}$. Only four males fell within the mean values for sperm concentration $(19.7 \pm$ 4.9 million $/ \mathrm{ml}$ for Siberian, $47.4 \pm 6.3$ million $/ \mathrm{ml}$ for Sumatran); the rest produced low concentrations of $<1-4$ million sperm $/ \mathrm{ml}$.

For the eight male South China tigers with motile sperm, the percentage of motile sperm was normal, ranging from 50 to 80 per cent (normal range 50-90 per cent). When sperm were rated for forward movement on a $0-5$ scale, with 5 being rapid forward movement, the status ratings varied from 2.0 to 3.5 (normal mean $=4$, range $=3-5$ ). Although the percentage of sperm with abnormal morphologies could not be evaluated for all samples, reports by Chinese zoo staff suggest that 65 per cent show abnormalities (normal mean $=22-40$ per cent). Together, these data suggest that eight of the 11 male South China tigers evaluated have low concentrations of normal, highly motile sperm.

Samples from the six males that produced motile sperm were cryopreserved and stored in the CAZG Genome Resource Bank (GRB) at Shanghai Zoo. A second GRB storage site needs to be selected, staff responsibilities specified, a GRB policy developed, and biosamples (sperm, tissue, hair and blood products) banked from every tiger while there is still time (reviewed in Wildt et al., 1995). These samples could be used for future DNA analysis, disease screening and assisted reproduction procedures.

\section{Captive population trends}

After verifying tiger identities, the number of South China tigers in the International Tiger Studbook rose from 76 to 264 individuals. Fiftyeight per cent (109 of 188) of these additions were neonatal deaths. The revised studbook ( $L i, 1995)$ was renumbered, submitted to the 
International Tiger Studbook Keeper and published in the 1995 International Tiger Studbook (Müller and Wesuls, 1995). The database has allowed a comprehensive analysis of the captive population for the first time.

The current captive population is based upon six wild-caught founders (two males and four females) brought into captivity over 25 years ago. Among these, genetic representation is unequal, with two founders accounting for over 62 per cent of the genetic material in the population. A gene drop analysis using the GENES software program (by Robert Lacy) indicated that this represented 2.312 founder genome equivalents, with only 78 per cent of the original gene diversity retained in the current population. (By contrast, the North American and European Siberian tiger populations each retain 96 per cent, the North American Sumatran tiger population retains 91 per cent and the European Sumatran tiger population retains 87 per cent; Brady, 1995; Christie, 1995; Traylor-Holzer, 1996.)

In the past, the management of South China tigers was based upon the needs of each zoo and that zoo's relative success in breeding certain individuals (e.g. Xiang, 1987). This approach is insufficient for the long-term maintenance of a genetically and demographically healthy captive population. The typical pattern in China has been to breed the same pairs continually, producing as many as 13 litters for one pair, at the expense of breeding other tigers. Thirty-six of the current 46 adult tigers have not yet produced any offspring and many have never been paired with a potential mate. Thus, priority must be given to the breeding of genetically valuable tigers to prevent further loss of genetic diversity and to pair potential breeders with mates to increase population growth. Further inbreeding must be minimized because there is evidence that inbreeding depression may be affecting the population (e.g. low sperm quality, high neonatal mortality, male-biased sex ratio). The mean inbreeding coefficient of the population is 0.2500 (the same level of inbreeding as a parent-offspring or full sibling mating), with some individuals being as high as 0.4218 . Inbreeding cannot be completely avoided be- cause 42 of the 50 captive tigers trace their ancestry back to founders SB Nos. 3 and 26. To accomplish these objectives, some of the current breeding individuals need to be given new mates to maximize genetic benefits and reproductive output (Traylor-Holzer and Tilson, 1996).

No net population growth has occurred in the captive population over the past 10 years. Furthermore, there are only eight animals under the age of 3 years, producing a bottleneck in the age structure of the population. If too few cubs are produced over the next several years, this will result in a shortage of breeding-age tigers in the future, leading to population decline. Compounding the problem is the current skewed male : female ratio (1.6:1). Fecundity declines at an earlier age for females than for males, dropping off rapidly at 12 years of age. Breeding-age females (4-11 years) are therefore a limiting factor for population growth; currently there are only nine female tigers in this age range. We calculate that $6-8$ breedings are needed each year to prevent population decline and more are needed to expand the population. Thus, every breeding age female should be mated now.

At least five surviving cubs are needed each year to balance adult mortality. Mortality within the first 6 months is relatively high at 52 per cent (over the past 10 years); this rate varies substantially among institutions and animal pairs (up to 90 per cent in some cases) and may or may not be attributable in part to inbreeding depression. Four to five litters per year will be necessary to keep the population stable, more to produce population growth. In contrast, no litters were produced in 1993, three in 1994 and two in 1995. Five litters were born in 1996 (after development of the masterplan), resulting in four surviving cubs.

It is not known whether the limiting factor on reproduction over the past several years has been a lack of cage space, too few breeding attempts or the failure of paired animals to reproduce. Whatever the cause, the recent low reproductive output of this population must be corrected. If it is simply a matter of differences in tiger management procedures among institutions or inadequate nutrition, this can 
be remedied easily. If it is a matter of reproductive variability among individuals or incompatibility among pairs of tigers, the problem can be resolved but not immediately. If low reproduction is a matter of inbreeding depression, there may be no easy solution because the population is already inbred and there are no or few available founders to revitalize the captive population.

To improve the situation, Chinese zoos need to manage the South China tiger as one population. The CAZG has already responded by forming a new tiger management committee, selected a co-ordinator and drafted a preliminary masterplan based upon institutional cooperation (Wang et al., 1995). This sets a precedent; crisis management in Chinese zoos for endangered species has been guided by the development of large centralized breeding facilities (Anon., 1994a). Since 1984 the South China tiger captive conservation programme has been based on first constructing a large breeding and research facility before taking other conservation action (CAZG, 1995). An analysis of the current and potential carrying capacity of the CAZG zoos at the masterplanning workshop demonstrated that there is sufficient space within the participating zoos to meet their programme goals, without the need to build an expensive central facility.

\section{Discussion}

Summary of the wild population

Although some field information is available on the distribution and status of wild South China tigers, it is difficult to interpret because the published data were for the most part presented anecdotally. This precludes a comparative analysis of research reports conducted at various sites for varying amounts of time. The common denominator in all these reports is that no researcher saw a tiger. Furthermore, no information was provided about tiger prey availability or the quality of potential tiger habitat, both of which are critically valuable in evaluating the potential for tiger survival (Karanth and Sunquist, 1992; Karanth, 1997; Sunquist et al., 1997).
What remains to be done is to assess the status and distribution of wild tigers and their prey and to evaluate the quality and extent of potential tiger habitat using a standardized field methodology (Karanth, 1995; also see results of methodology workshop organized by T. Maskey, Director General, Department of National Parks and Wildlife Conservation, Nepal). Once this information is made available to the Chinese conservation authorities, a conservation action plan needs to be developed that addresses the following questions.

- Are there sufficient numbers of wild populations of sufficient size that their protection (and protection of their prey and habitat) will allow natural expansion needed for long-term viability? And if so, how will effective protection be achieved?

- If the wild populations are too small and too fragmented to be viable with protection alone, do other options for their recovery need to be developed? If so, what are these options and which one is the best choice?

- Is there even a wild population left?

Once these questions are answered, other more comprehensive recommendations presented elsewhere should be considered, for example by Yu et al. (1987; for South China tigers specifically) and by the Wildlife Conservation Society (WCS), Indonesian Ministry of Forestry and the IUCN Cat Specialist Group (for tigers generally; Ministry of Forestry, 1994; Norchi and Bolze, 1995; Nowell and Jackson, 1996).

\section{Summary of the captive population}

Improvement of the South China tiger captive programme is vital to prevent further loss of genetic diversity. Our preliminary evaluations indicate that the most critical issue for the captive population is to increase its reproductive output and minimize inbreeding. Overall, the captive population is declining, the average inbreeding coefficient is high and a significant number of adult males have poor-quality sperm. Tan (1987) came to essentially the same conclusions and concluded that these problems could only be solved by implementing a nation-wide breeding programme, a step that has now been taken by the CAZG. 
The CAZG earlier identified the conservation of the South China tiger as a priority programme as part of China's Bio-Diversity Conservation Action Plan. In 1995 specific recommendations for the captive population were presented in its South China Tiger Ex-Situ Conservation Outline (Wang et al., 1995). In brief these recommendations included action on the points listed below, some of which has already been accomplished.

- Establish a South China tiger studbook, perform demographic and genetic analyses on the captive population, and develop a 5year masterplan implemented by a co-ordination committee among Chinese zoos.

- Improve tiger physical facilities at these zoos and provide technical training for staff in tiger management, husbandry and veterinary care.

- Develop links with international organizations that will assist the CAZG technically and financially to achieve the above goals.

- To promote within China the importance of developing a comprehensive, professional ex situ programme for South China tigers.

A proposal that addressed the process for providing additional training for CAZG zoos managing South China tigers was developed in 1996 but not funded because some international conservation funding agencies were unconvinced that there was sufficient Chinese government support. The recent and remarkable progress of the CAZG (under the Chinese Ministry of Urban and Rural Construction and Environmental Protection) in developing its South China tiger programme counter-indicates this belief (Wang et al., 1995). A new research initiative for 1997 has received support from the Save the Tiger Fund to assist in the development of management strategies for captive South China tigers.

\section{Conclusion}

If action is not taken immediately, China runs the risk of losing both wild and captive South China tigers. We must not lose sight of the fact that the wild population may already be functionally extinct. The captive population, for better or for worse, may be all that is left against total extinction of this subspecies. To paraphrase the words of a noted environmental philosopher (Leopold, 1953), the first rule of intelligent tinkering is not to throw away any of the pieces. Thus, it is uncertain if the South China tiger can be saved, but now is the time for action; next year may be too late.

\section{Acknowledgements}

This article is an outcome of our involvement in assisting the Chinese Association of Zoological Gardens in developing its South China tiger masterplan. Zheng Shuling, Wang Menghu, Xie Zhong and Zhao Qingguo from the CAZG facilitated our visits to China. We are especially thankful to zoo directors Shi Xin Quan (Shanghai Zoological Garden), Wu Ming Cheng (Suzhou Zoo), Yao Minda (Chongqing Zoological Gardens), Li Genhong (Guangzhou Zoological Gardens), and their staff for hosting the IUCN/SSC CBSG tiger teams, and to Ulysses Seal for initiating this process. This article was in part made possible by the dedicated efforts of our colleagues Douglas Armstrong (Henry Doorly Zoo), Ann Byers (CBSG), Gerald Brady (Potter Park Zoo), Eric Miller (St Louis Zoo) and Jansen Manansang (Taman Safari Indonesia). Peter Jackson, IUCN Cat Specialist Group Chair, provided important reference documents. We thank the Save the Tiger Fund, a special partnership between the National Fish and Wildlife Foundation and Exxon Corporation, for its support of the site visits to China and its future commitments to make a difference.

\section{References}

Anon. 1994a. China protects wildlife. Beijing Review, August. 29, 30-31.

Anon. 1994b. Proposal to register the first commercial captive-breeding operation for Siberian Tiger. Submitted to the CITES Secretariat by the People's Republic of China and the Breeding Center of Felidae Animals of Hengdaohezi, People's Republic of China.

Armstrong, D., Miller, E., Byers, O., Brady, G., Traylor-Holzer, K. and Tilson, R. 1996. International cooperation with range country efforts to conserve tigers (Panthera tigris) and the veterinarian's role. American Association of Zoo Veterinarians Annual Conference Proceedings, November 3-8, 1996. pp. 532-553.

Brady, G. 1995. SSP Sumatran Tiger Studbook 1995. Potter Park Zoo, Lansing, MI.

Byers, A., Armstrong, D., Miller, E. and Traylor- 
Holzer, K. 1996. Reproductive evaluation and genome resource banking. In Medical, Reproductive and Management Evaluation of South China Tigers in China (eds R. Tilson, D. Armstrong, E. Miller, A. Byers, K. Traylor-Holzer, G. Brady, Wang Menghu and Xie Zhong), pp. 47-49. Minnesota Zoo, Apple Valley, MN.

CAZG. 1995. South China tiger ex-situ conservation outline. In South China Tiger Studbook Analysis and Masterplan Report (eds Wang Menghu, R. Tilson, K. Traylor-Holzer, J. Manansang and U. Seal), pp. 29-33. Minnesota Zoo, Apple Valley, MN.

Christie, S. 1995. European Tiger Studbook. London Zoo, London.

Day, M. 1994. Bones of Contention: Part I. The Tiger Trust, UK.

Espinoza, P.E., Mann, M.J., Yates, B. and Elliot, L. 1994. Preliminary forensic analysis of the wildlife content of patented Asian medicines. In Prescription for Extinction: Endangered Species and Patented Oriental Medicines in Trade-A TRAFFIC Network Report (eds A. L. Gaski and K. A. Johnson), pp. 94-101. TRAFFIC, Washington, DC.

Franklin, N., Sriyanto, Bastoni, Siswomartono, D., Manansang, J. and Tilson, R. (in press). Last of the Indonesian tigers: a cause for optimism. In Tigers 2000 (eds J. Seidensticker, P. Jackson and S. Christie). Cambridge University Press, Cambridge.

Griffiths, M. 1994. Population density of Sumatran tigers in Gunung Leuser National Park. In Sumatran Tiger Population and Habitat Viability Analysis Report (eds R. Tilson, K. Soemarna, W. Ramono, S. Lusli, K. Traylor-Holzer and U. Seal), pp. 93-101. Indonesian Forest Protection and Nature Conservation and IUCN/SSC Conservation Breeding Specialist Group, Jakarta and Apple Valley, MN.

Gui Xiaojie and Meng Sha. 1993. The Challenge and Strategies for Management of the South China Tiger Panthera tigris amoyensis. Paper presented at the Global Tiger Forum, 4 March 1994, New Delhi, India.

Henley, G. and Mills, J. (in press). The tiger in trade: How much and what to do about it? In Tigers 2000 (eds J. Seidensticker, P. Jackson and S. Christie). Cambridge University Press, Cambridge.

Herrington, S. 1987. Subspecies and the conservation of Panthera tigris: preserving genetic heterogeneity. In Tigers of the World: The Biology, Biopolitics, Management, and Conservation of an Endangered Species (eds R. Tilson and U. Seal), pp. 51-63. Noyes Publications, Park Ridge, NJ.

Jackson, P. 1993. The status of the tiger in 1993 and threats to its future. Cat News, 19, 5-11.

Jackson, P. 1996. Concern about Chinese tiger programme. Cat News, 25, 13-14.

Karanth, K.U. 1995. Estimating tiger Panthera tigris populations from camera-trap data using capture- recapture models. Biological Conservation, 71, 333-338.

Karanth, K.U. (in press). Prey density as a critical determinant of tiger population viability. In Tigers 2000 (eds J. Seidensticker, P. Jackson and S Christie). Cambridge University Press, Cambridge.

Karanth, K.U. and Sunquist, M.E. 1992. Population structure, density and biomass of large herbivores in the tropical forests of Nagarahole, India. Journal of Tropical Ecology, 8, 21-35.

Kenney, J., Smith, J., Starfield, A. and McDougal, C. 1995. The long-term effects of tiger poaching on population viability. Conservation Biology, 9, 1127-1133.

Koehler, G. 1991. Survey of Remaining Wild Population of South China Tigers. WWF Project 4152/China Final Project Report.

Leopold, A. 1953. Round River. Oxford University Press, New York.

Li Wenhua and Zhao Xianying. 1989. China's Nature Reserves. Foreign Languages Press, Beijing.

Li Yinghong. 1995. South China Tiger Studbook. Chongqing Zoo, Chongqing, China.

Liu Xin Chen. 1993. A plans (sic) of training Siberian Tigers and living in the wild and release to their natural habitat. Submitted to the IUCN Cat Specialist Group by the Breeding Center of Felidae Animals of Hengdaohezi, People's Republic of China.

Lu Houji. 1987. Habitat availability and prospects for tigers in China. In Tigers of the World: The Biology, Biopolitics, Management, and Conservation of an Endangered Species (eds R. Tilson and U. Seal), pp. 71-74. Noyes Publications, Park Ridge, NJ.

Lu Houji and Sheng Helin. 1986. Distribution and status of the Chinese tiger. In Cats of the World: Biology, Conservation and Management (eds S. Miller and D. Everett), pp. 51-58. National Wildlife Federation, Washington, DC.

Mainka, S. and Mills, J. 1995. Wildlife and Traditional Chinese Medicine-supply and demand for wildlife species. Journal of Zoo and Wildlife Medicine, 26, 193-200.

Martin, E.B., Liu Xin Chen and Chen Ke Lin. 1991. The breeding centre for Siberian tigers in China. International Zoo News, 229 (38/4), 11-14.

McDougal, C. 1977. The Face of the Tiger. Rivingdon Books \& Andre Deutsch, London.

Miquelle, D., Smirnow, E.N., Myslenko, A., Merrill, T., Shevlakov, A., Quigley, H. and Hornocker, M.G. (in press). Habitat relationships of the Amur tiger. In Tigers 2000 (eds J. Seidensticker, P. Jackson and S. Christie). Cambridge University Press, Cambridge.

Mills, J. and Jackson, P. 1994. Killed for a Cure: $A$ Review of the Worldwide Trade in Tiger Bone. TRAFFIC International, Cambridge, UK.

Ministry of Forestry. 1994. Indonesian Sumatran Tiger 
Conservation Strategy. Ministry of Forestry, Jakarta.

Muller, P. 1994. International Tiger Studbook. Leipzig Zoo, Leipzig.

Muller, P. and Wesuls, P. 1995. International Tiger Studbook. Leipzig Zoo, Leipzig.

Norchi, D. and Bolze, D. 1995. Saving the Tiger: A Conservation Strategy. WCS Policy Report Number 3. Wildlife Conservation Society, New York.

Nowell, K. and Jackson, P. 1996. Wild Cats: Status Survey and Conservation Action Plan. International Union for Conservation of Nature and Natural Resources, Gland.

Sankala, K. 1979. Tigers in the wild - their distribution and habitat preferences. In International Symposium on the Management and Breeding of the Tiger (eds S. Seifert and P. Muller), pp. 43-59. Leipzig Zoo, Leipzig.

Santiapillai, C. and Widodo, S.R. 1987. Tiger numbers and habitat evaluation in Indonesia. In Tigers of the World: The Biology, Biopolitics, Management, and Conservation of an Endangered Species (eds R. Tilson and U. Seal), pp. 85-91. Noyes Publications, Park Ridge, NJ.

Seal, U., Soemarna, K. and Tilson, R. 1994. Population biology and analyses for Sumatran tigers. In Sumatran Tiger Population and Habitat Viability Analysis Report (eds R. Tilson, K. Soemarna, W. Ramono, S. Lusli, K. TraylorHolzer and U. Seal), pp. 45-70. Indonesian Forest Protection and Nature Conservation and IUCN/SSC Conservation Breeding Specialist Group, Jakarta and Apple Valley, MN.

Smith, J.L.D. 1978. Smithsonian Tiger Ecology Project. Unpublished report no. 13. Smithsonian Institution, Washington, DC.

Sunquist, M.E. 1981. The social organization of tigers (Panthera tigris) in Royal Chitwan National Park, Nepal. Smithsonian Contrib. Zool. 336, 1-98.

Sunquist, M.E., Karanth, K.U. and Sunquist, F. (in press). Ecology, behaviour and resilience of the tiger and its conservation needs. In Tigers 2000 (eds J. Seidensticker, P. Jackson and S. Christie). Cambridge University Press, Cambridge.

Tan Bangjie. 1987. Status and problems of captive tigers in China. In Tigers of the World: The Biology, Biopolitics, Management, and Conservation of an Endangered Species (eds R. Tilson and U. Seal), pp. 134-148. Noyes Publications, Park Ridge, NJ.

Tilson, R. Armstrong, D., Miller, E., Byers, A., Traylor-Holzer, K., Brady, G., Wang Menghu and Xie Zhong. 1996. Medical, Reproductive and Management Evaluation of South China Tigers in China. Minnesota Zoo, Apple Valley, MN.

Tilson, R., Brady, G., Traylor-Holzer, K. and Armstrong, D. (eds). 1995. Management and Conservation of Captive Tigers Panthera tigris.
Minnesota Zoo, Apple Valley, MN.

Tilson, R. and Seal, U. (eds). 1987. Tigers of the World: The Biology, Biopolitics, Management, and Conservation of an Endangered Species. Noyes Publications, Park Ridge, NJ.

Traylor-Holzer, K. 1996. Evaluation of the AZA Tiger SSP and its relation to the global Siberian tiger programme. Proceedings of the Special Meeting of the Amur Tiger EEP, 2-3 November 1995, Moscow.

Traylor-Holzer, K. and Tilson, R. 1996. Population management evaluation. In Medical, Reproductive and Management Evaluation of South China Tigers in China (eds R. Tilson, D. Armstrong, E. Miller, A. Byers, K. Traylor-Holzer, G. Brady, Wang Menghu and Xie Zhong), pp. 51-57. Minnesota Zoo, Apple Valley, MN.

Wang Menghu, Tilson, R., Traylor-Holzer, K, Manansang, J. and Seal, U. 1995. South China Tiger Studbook Analysis and Masterplan. Minnesota Zoo, Apple Valley, MN.

Wang Zong-Yi and Wang Sung. 1986. Distribution and recent status of the Felidae in China. In Cats of the World: Biology, Conservation and Management (eds S. Miller and D. Everett), pp. 201-209. National Wildlife Federation, Washington, DC.

Wildt, D., Byers, A., Johnston, L., Howard, J., Willis, K., O'Brien, S., Tilson, R., Rall, W. and Seal, U. 1995. Tiger Genome Resource Banking (GRB) Action Plan: Global Need and a Plan for North America and Indonesia. IUCN/SSC Conservation Breeding Specialist Group and the American Zoo and Aquarium Association, Apple Valley, MN.

Xiang Peilon. 1987. Captive management of South China tigers (Panthera tigris amoyensis) in China. In Tigers of the World: The Biology, Biopolitics, Management, and Conservation of an Endangered Species (eds R. Tilson and U. Seal), pp. 317-322. Noyes Publications, Park Ridge, NJ.

Xiang Peilon, Tan Bangie and Jia Xianggang. 1987. South China tiger recovery program. In Tigers of the World: The Biology, Biopolitics, Management, and Conservation of an Endangered Species (eds R. Tilson and U. Seal), pp. 323-328. Noyes Publications, Park Ridge, NJ.

Yu Si-mian, Wang Lili, Wu ?ying, Deng Shi-fang, and Deng Shi-song. 1987. The environmental status of the South China tiger in Guangdong Province. Submitted to the IUCN Cat Specialist Group.

Ronald Tilson and Kathy Traylor-Holzer, Minnesota Zoo, 13000 Zoo Blvd, Apple Valley, MN 55124, USA

Qiu Ming Jiang, Kunming Institute of Zoology, Chinese Academy of Sciences, Xiamacun, Kunming, Yunnan 650223, People's Republic of China. 